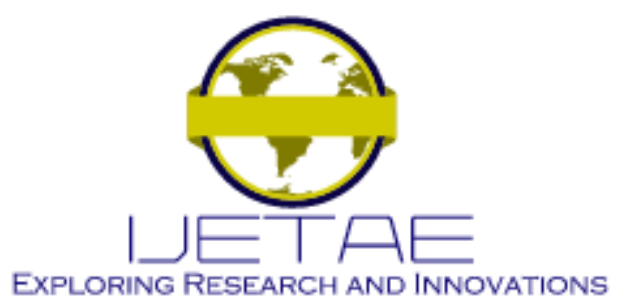

International Journal of Emerging Technology and Advanced Engineering

Website: www.ijetae.com (E-ISSN 2250-2459, Scopus Indexed, ISO 9001:2008 Certified Journal, Volume 11, Issue 11, November 2021)

\title{
Convergence Study of High Refractive Index Polarized Glasses Lens with Photochromic and UV Blocking Function
}

\author{
Doo Hee Han \\ Industrial Technology Convergence Research Institute, Chungwoon University, 113, Sukgol-ro, Michuhol-gu, Incheon, \\ R.O. Korea, 22100
}

\begin{abstract}
Those who use convex or concave lenses should use sunglasses made from regular spectacle lenses. In this case, it uses a surface coating to block UV rays, so it is relatively vulnerable to UV protection. To this end, we developed a spectacle lens that can completely block ultraviolet light and suppress blue light by using a monomer that completely blocks the area below $410 \mathrm{~nm}$ and has a sunglasses function through photochromic function. A spectacle lens with photochromic, polarization and UV blocking functions was developed using a monomer with a high refractive index of 1.67. In the photochromic property, a recovery time of 2 minutes for light reaction and 5 minutes for dark reaction was obtained. Five layers of anti-reflection coating were applied to the surface of the lens to reduce the transmittance in the visible light region to 0.1 or less. ITO was applied to give an electromagnetic wave shielding function, and the thickness and conductivity of ITO were proportional to the result. The blue light emitted from the LED is reduced by more than $30 \%$ to reduce eye fatigue. UV rays were completely blocked below $410 \mathrm{~nm}$.
\end{abstract}

Keywords-Ultra violet, Blue light, Sunglass, Photochromic, Eyeglass lenses

\section{INTRODUCTION}

Wear sunglasses to prevent glare. Sunglasses are very important to block UV rays. If UV protection is not used to reduce the amount of light, the pupils dilate, allowing more UV light to enter the eye. Methods to reduce sunlight include photochromic lenses containing photochromic materials [1-4], polarizing lenses using polarizing films [57], and methods of mixing dark colors have been studied and used. Recently, it has been found that blue light emitted from LEDs installed in smartphones and computer monitors is not good for the eyes, so blue light blocking lenses are emerging [8-11]. Photochromic and UVblocking spectacle lens materials cannot be mixed. Because photochromic materials require UV light, but UV-blocking materials must block UV light.

A special method is required to solve this. In addition, modern people who have used electronic devices such as smartphones for a long time need an electromagnetic wave shielding function. If the refractive index of $\mathrm{ZrO} 2$ and ITO (indium tin oxide) is the same and applied to the antireflection multi-layer coating, the electromagnetic wave shielding function can be added to the spectacle lens. have.

UVA, UVB, and UVC are the ultraviolet rays emitted by the sun. The earth's ozone layer absorbs 97 99\% and the rest reaches the surface of the earth, and $98.7 \%$ of the ultraviolet rays that reach the surface are UVA. In addition, gas discharge tubes dedicated to ultraviolet LEDs and ultraviolet laser devices also emit ultraviolet rays. In general, when the human body is exposed to ultraviolet rays, short-term or long-term skin damage such as erythema, burns, wrinkles, freckles, keratinization, and skin cancer may occur. Due to the recent destruction of the ozone layer by air pollutants and the increase in leisure activities, the human body is more exposed to the dangers of ultraviolet rays, and accordingly, efforts to protect the human body from ultraviolet rays are becoming more urgent. The shorter the wavelength of ultraviolet light, the more harmful it is to the body. This is because the energy of electromagnetic waves is inversely proportional to the wavelength. Energy is proportional to the frequency. That is, $E=h f(E$ : energy, h: Planck's constant, f: frequency). UV protection coating is applied to the lens to achieve UV protection, but when the coating is peeled off, the UV blocking function is reduced and it is harmful to the eyes. Therefore, if a lens is manufactured by containing a material having a UV blocking function in the monomer, which is the raw material of spectacle lenses, the UV blocking function is maintained even if the surface is damaged. On the other hand, the technology to completely block UV rays has gradually developed and lenses with a blocking function up to $400 \mathrm{~nm}$ have been developed, but they are mainly made by Japanese companies.

The development of a lens that completely blocks ultraviolet rays below $410 \mathrm{~nm}$ is necessary for healthy eyes 


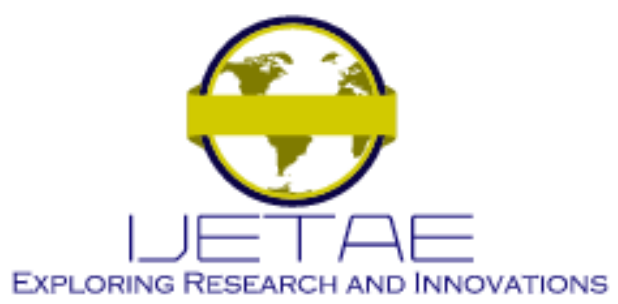

International Journal of Emerging Technology and Advanced Engineering

Website: www.ijetae.com (E-ISSN 2250-2459, Scopus Indexed, ISO 9001:2008 Certified Journal, Volume 11, Issue 11, November 2021)

[12-16].

\section{Functional SubStances APPlied To DeVElopment}

\section{A. Monomer for UV protection}

A benzotriazole-based UV absorber with a molecular weight of $250-330 \mathrm{~g} / \mathrm{mol}$ to absorb UV rays, $\mathrm{B}$, a benzotriazole-based UV absorber with a molecular weight of 300-320 $\mathrm{g} / \mathrm{mol}$, and benzotriazole-based UV absorber with a molecular weight of 430-450 g/mol A UV absorber in which $\mathrm{C}$, which is a benzotriazole-based UV absorber, was mixed was used. Table 1 shows the types of UV blocking monomers.

TABLE I

UV BLOCKING MONOMER TYPE

\begin{tabular}{|c|c|c|}
\hline Type & Materials & Portion $(\%)$ \\
\hline \multirow{2}{*}{ A } & 1,6-diisocyanatohexane & 54 \\
\hline & 2,5-diisocyanatomethylbic & 46 \\
\hline \multirow{3}{*}{ B } & $\begin{array}{c}\text { 2,3-Bis(2-mercaptoethylthio)propane-1- } \\
\text { thiol }\end{array}$ & 84 \\
\hline & {$[1,4]$ Dithian-2-yl-methanethiol } & 10 \\
\hline & $\begin{array}{l}\text { 2-9[1,4]Dithian-2-ylmethylsulfanyl)- } \\
\text { ethanelthiol }\end{array}$ & 6 \\
\hline \multirow{3}{*}{$\mathrm{C}$} & Pentaerythritoltetrakis & 80 \\
\hline & $\begin{array}{l}\text { 3-Mercapto-propionic acid 3-hydroxy 2,2- } \\
\text { bis-propylester }\end{array}$ & 16 \\
\hline & $\begin{array}{l}\text { 3-Mercapto-propionic acid 3-hydroxy-2- } \\
\text { hydroxymethyl-2-propyl ester }\end{array}$ & 4 \\
\hline
\end{tabular}

\section{B. Photochromic Blockers}

Photochromic lenses are usually made by preparing a photochromic resin composition in which a photochromic compound is mixed with a radically polymerizable monomer and then curing the resin composition.

It is mainly applied to acrylics, which are easy to mix with photochromic compounds, and can make lenses with good color change performance and optical properties, mainly for medium and high refractive lenses. However, when the thickness of the lens is not uniform like a spectacle lens, there is a problem in that it is difficult to secure the uniformity of the coating. In the thick part of the lens, a lot of discoloration material is distributed, so the color density becomes thick while the discoloration sensitivity becomes dull. unevenness will occur. Therefore, a uniform thickness of the photochromic lens is required.

\section{Indium Tin Oxide}

Indium tin oxide is a mixture of indium oxide $\left(\operatorname{In}_{2} \mathrm{O}_{3}\right)$ and tin oxide $\left(\mathrm{SnO}_{2}\right)$, and generally has a ratio of $90 \%$ $\mathrm{In}_{2} \mathrm{O}_{3}$ and $10 \% \mathrm{SnO}_{2}$. It is often called transparent electrode or ITO. In a thin layer, it is transparent and colorless. In a lumpy state, it is yellowish-gray. The main characteristics of indium tin oxide are high electrical conductivity and good optical transparency. However, this feature only applies to thin films, and in the thick case, the charge carrier increases the metal's conductivity but reduces its transparency. Thin films of indium tin oxide are most commonly deposited on surfaces by electron beam deposition, vapor deposition, or sputtering techniques.

\section{Manufacture OF Spectacle Lenses And PERFORMANCE TEST}

\section{A. Manufacturing process of spectacle lenses}

1) Taping the upper mold.

2) Drop the discoloration composition on the upper mold recess.

3) A polarizing film is laminated on the color-changing composition placed in the concave part of the upper mold.

4) Pre-polymerize the color-changing composition. Prepolymerization is preheated to $15^{\circ} \mathrm{C}(5$ minutes $)$, followed by polymerization at $15^{\circ} \mathrm{C}(6$ hours $), 15$ to $60^{\circ}$ $\mathrm{C}(4$ hours $), 60^{\circ} \mathrm{C}(10$ hours $)$, and 60 to $15^{\circ} \mathrm{C}(2$ hours $)$.

$5)$ Widen the gap between the upper and lower molds to which the upper lens in the gel state and the polarizing film made by prepolymerizing the discoloration composition and tap again.

6) Inject the UV blocking composition through the space between the polarizing film and the lower mold.

7) Mainly polymerize the gel-like upper lens and UVblocking composition. This polymerization is preheated to $25^{\circ} \mathrm{C}$ for 5 minutes, at $25-40^{\circ} \mathrm{C}$ for 7 hours, at 40 - 


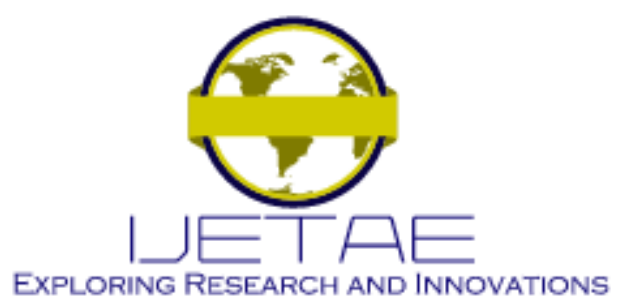

International Journal of Emerging Technology and Advanced Engineering

Website: www.ijetae.com (E-ISSN 2250-2459, Scopus Indexed, ISO 9001:2008 Certified Journal, Volume 11, Issue 11, November 2021)

$50^{\circ} \mathrm{C}$ for 3 hours, at $50-65^{\circ} \mathrm{C}$ for 2 hours, at $65-95^{\circ} \mathrm{C}$ for

3 hours, at $95-120^{\circ} \mathrm{C}$ for 1 hour, at $120^{\circ} \mathrm{C}$ for 2 hours, at $120-70^{\circ} \mathrm{C}$ for 2 hours

\section{Photochromic}

Photochromism refers to the fact that a substance that is normally clear and transparent changes to dark gray or brown when exposed to ultraviolet light. This phenomenon is caused by a photochromic material, which can be used to make color-changing lenses, color-changing tiles, and the like. Photochromic lenses react to ultraviolet and violet light and are mainly affected by ultraviolet light. Therefore, it is transparent or colorless in a room without the influence of UV rays, but changes to dark brown or gray under the influence of UV rays when exposed to sunlight. This is different from regular sunglasses that are equally dark in both dark and bright places. In general, the monomer determines the refractive index of the spectacle lens. In the vicinity of the refractive index of 1.5 , a material called CR39 was used, and in the vicinity of the refractive index of 1.6, a urethane-based monomer was used. A small amount of the photochromic material is mixed with this basic lens monomer. Various compounds are used for the photochromic compound. In general, the surface of plastic lenses is not strong enough to be easily scratched. Although many attempts have been made to compensate for this, in general, a silica component is coated on the surface of a plastic lens by immersing the lens in a solution in which the silica component is dissolved and taking it out. This method is called hard coating. Here, $\mathrm{SiO} 2$ and $\mathrm{ZrO} 2$ are alternately vacuum-deposited to add an anti-reflection function. Figure 1 shows the structure of a general spectacle lens. On the other hand, if ITO, a conductive material with the same refractive index as $\mathrm{ZrO} 2$, is used, electromagnetic wave protection can be provided. When a relatively large amount of the photochromic compound is used, the photochromic property is improved, but the surface hardness is weakened. Because of this problem, it is important to adjust the ratio of the basic monomer and the photochromic compound, which is a lens material. It is also important how to apply the thickness of the photochromic lens. In general, if you use prescription glasses, you use regular lenses to color them when making sunglasses.

In this case, there was a disadvantage that the color density was different because the thickness around the center and the edge were different. The photochromic layer also needs to maintain a constant thickness for the same reason. In this study, the problem was solved by placing a polarizing plate of a certain thickness on a certain photochromic layer and then making a layer that blocks ultraviolet and blue light. This is the first attempt according to the results of the domestic market research. This is because adhesion is not easy, but by controlling the polymerization temperature and time with pure monomers and a polarizing film, the adhesion was successful. Figure 1 illustrates the surface coating of spectacle lenses.

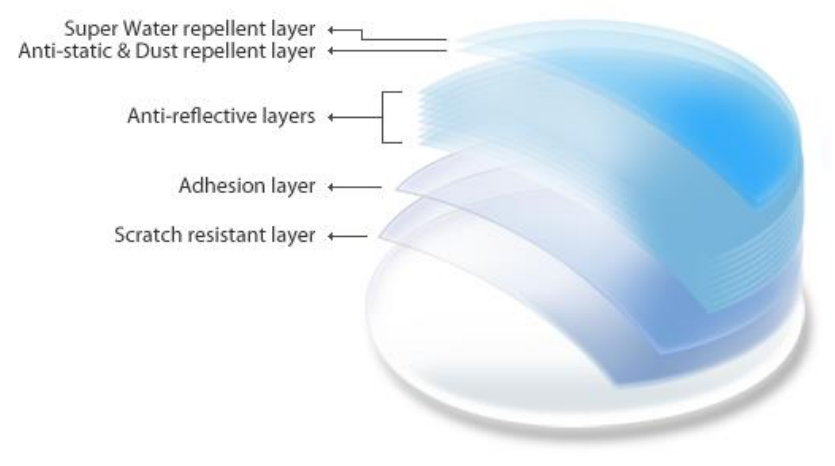

Fig. 1 The structure of spectacle lens

Photochromism was measured using Jasco's MV-3150 and LUS-373. The MV-3150, a portable spectrophotometer, can measure a spectrum at least every $5 \mathrm{msec}$. By measuring the spectrum at high speed, the time required for product inspection can be reduced by monitoring production lines, etc. and mapping measurements. Because it uses a diffraction grating driving function and optical fiber-free structure, it is compact, easy to handle, and can be widely used for field measurements and other applications. The portable spectrophotometer MV-3000 series consists of a spectrophotometer body and a light source. MV-3100/3150 measures between 200 and $800 \mathrm{~nm}$ in wavelength range, and LUS-373 uses light source D $2+$ halogen light source in wavelength range of 200 to 1600 $\mathrm{nm}$. When monitoring long lines, a pseudo-dual-beam mechanism can be integrated into the accessory to increase reliability. A reference calibration was performed between measurement and measurement using an optical pathswitching mirror.

Since the stability of the spectrophotometer is affected by the ambient temperature, this mechanism is indispensable for long-term measurements such as date 


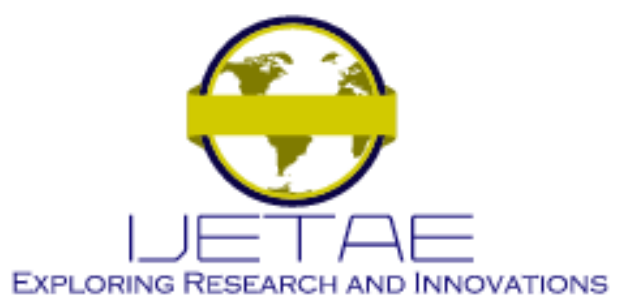

International Journal of Emerging Technology and Advanced Engineering

Website: www.ijetae.com (E-ISSN 2250-2459, Scopus Indexed, ISO 9001:2008 Certified Journal, Volume 11, Issue 11, November 2021)

crossings. The change in transmittance with respect to the time of the light reaction and the dark reaction was measured using this device, and the result shown in Figure 2 was obtained. Here, it can be seen that the light reaction takes about 2 minutes and the dark reaction takes about 5 minutes.

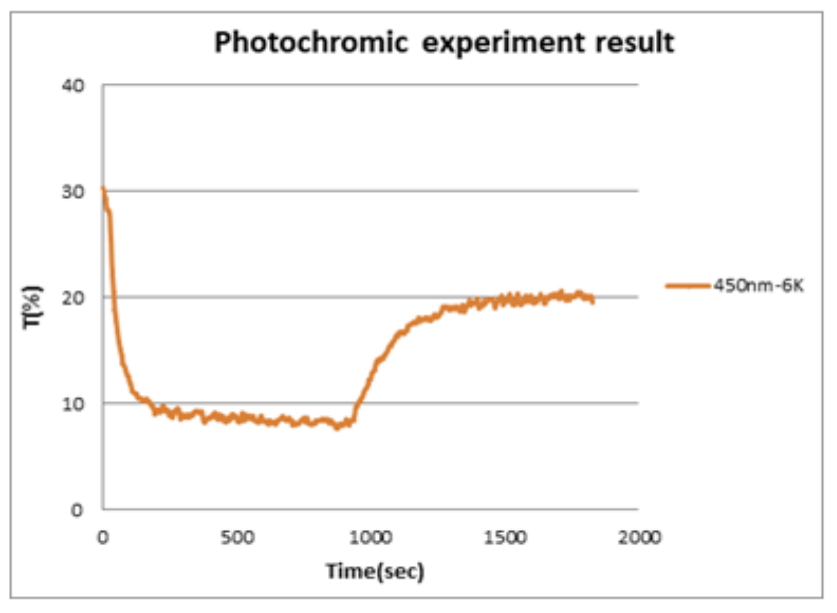

Fig. 2 Photochromism test result

On the other hand, it can be confirmed that the transmittance is at least less than $10 \%$ when the lens is darkened due to the light reaction.

\section{Polarization}

Polarization emits light that only vibrates in a certain direction. In general, sunlight vibrates with the same magnitude in all directions. When sunlight passes through a polarizer, it vibrates in one direction, which is said to be polarized. Scattered or surface-reflected light is polarized in a specific direction. Most of them are horizontally polarized, so if the polarizer is positioned vertically, the polarizer cannot pass through. It is for this reason that polarized sunglasses appeared. Polarized sunglasses can almost completely reduce reflections from asphalt or other reflections from driving at night. The method of bonding the polarizing film to the lens is sometimes attached using an adhesive, but has a disadvantage in that the transmittance is very poor. An improved method is a method of attaching a polarizing film by heating.

In this case, there is no problem in transmittance, but there is a problem in that the polarizing film is easily broken. There is a method of placing a polarizing film in the monomer. Among them, there is a method of making a lens by putting a polarizing film inside a mold using a gasket mold, and molding a plastic containing a polarizing film by injecting a monomer into the mold. Since manual work requires a lot of skill, the technique of adjusting the upper and lower jigs using a pneumatic device is also used. However, it is basically impossible to reduce the thickness of the front side of the polarizing film to about $1 \mathrm{~mm}$ by using a jig. This method has a disadvantage in that the thickness of the lens becomes thicker than necessary. Therefore, a new method that does not use a gasket mold is needed. In this paper, a method was used to make the front part of the polarizing film less than $1 \mathrm{~mm}$ by using adhesive tape instead of a gasket mold. That is, a method was used that does not require an upper and lower jig, an upper and lower supporter, a notch groove of the polarizing film, and a method capable of simply manufacturing a polarizing lens by prepolymerization and main polymerization. Using this method, the polarizing film can be uniformly combined with the lens, and it does not protrude out of the lens, so that it can be coated uniformly.

It is difficult to impart polarization to the spectacle lens material. Heat was applied to match the curvature of the polarizing film and the outer curvature of the lens. A polarizing film was placed on the back side of the photochromic layer of $1 \mathrm{~mm}$. A monomer having a UV blocking function was put inside the polarizing film, and adhesive strength was maintained through the polymerization process. A polarizing film for sunglasses manufactured by PT\&T Co., Ltd. was used as a polarizing film for sunglasses. The product name was Gray-37, and the polarization degree (PE) was 99.07 in the visible light range of 400-700 nm. Figure 5 shows the MPC-2200 multipurpose large sample compartment used for measurements. The measurement wavelength range is 240 to $800 \mathrm{~nm}$ (MPC-2200). The maximum sample size is $305 \mathrm{~mm} \times 50$ $\mathrm{mm} \mathrm{T}$ or $204 \mathrm{~mm} \mathrm{dia.} \times 300 \mathrm{~mm} \mathrm{~T}$, in the case of reflection, the diameter is $305 \mathrm{~mm} \times 50 \mathrm{~mm} \mathrm{~T}$. The color, polarizing efficiency, and spectrum of the polarizing film used to manufacture the lens were measured. Figure 3 shows the spectrum of the polarization experiment, and Figure 4 shows the color and spectral diagram. The polarizing efficiency was $99.07 \%$. 


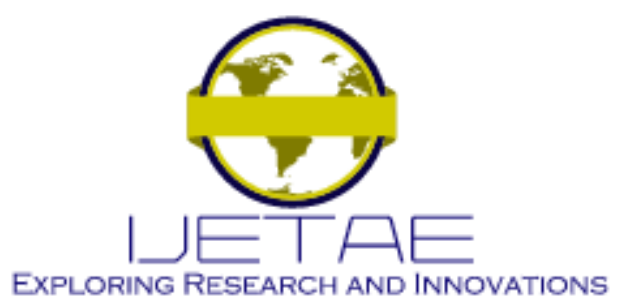

International Journal of Emerging Technology and Advanced Engineering

Website: www.ijetae.com (E-ISSN 2250-2459, Scopus Indexed, ISO 9001:2008 Certified Journal, Volume 11, Issue 11, November 2021)

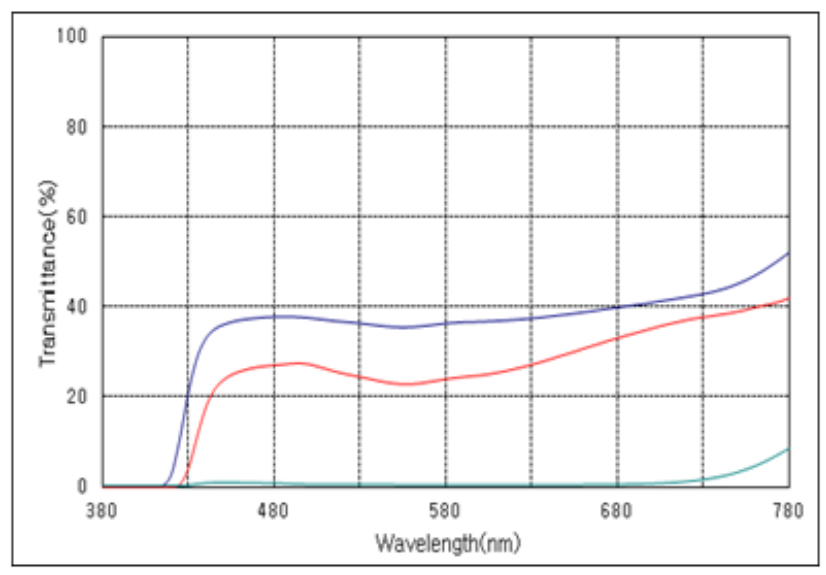

Fig. 3 Polarization measurement spectral data

- Luminous transmittance

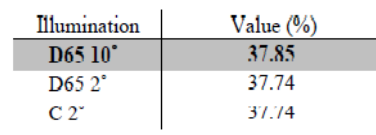

- Color

\begin{tabular}{|c|c|c|c|c|c|c|c|}
\hline Tllumination & $\mathrm{Y}$ & $\mathrm{x}$ & $\mathrm{y}$ & CIF I.* & CIF a* & CIF b* & $\mathrm{PF}(400 \sim 700 \mathrm{~nm})$ \\
\hline Do5 $10^{\circ}$ & 37.85 & 0.3101 & 0.3269 & 67.91 & 0.07 & -1.67 & \multirow{3}{*}{$99.07 \%$} \\
\hline D $652^{\circ}$ & 37.74 & 0.3092 & 0.3240 & 67.83 & 0.49 & -1.90 & \\
\hline $\mathrm{C} 2^{\circ}$ & 37.74 & 0.3065 & 0.3111 & 67.83 & 0.55 & -1.90 & \\
\hline
\end{tabular}

* PE : Polarizing cfficicncy

Fig. 4 Polarizing efficiency measurement

\section{E. Ultraviolet ray protection}

Ultraviolet ray has a wavelength of 100 to $400 \mathrm{~nm}$, shorter than visible light, but longer than X-rays. The gas discharge tube of an ultraviolet LED or ultraviolet laser device is the only mechanism that emits ultraviolet rays. In general, when the human skin is exposed to ultraviolet rays, skin damage such as redness, burns, wrinkles, freckles, and skin keratinocyte phenomena may occur. In particular, exposure to UVA is known to weaken the immune system and cause skin cancer. Table 2 shows the types and properties of UV rays.
TABLE II

TYPES OF ULTRAVIOLET RAYS

\begin{tabular}{|l|l|l|}
\hline Name & Wavelength & Energy/ photon \\
\hline UVA & $400-315 \mathrm{~nm}$ & $3.10-3.94 \mathrm{eV}$ \\
\hline UVB & $315-280 \mathrm{~nm}$ & $3.94-4.43 \mathrm{eV}$ \\
\hline UVC & $280-100 \mathrm{~nm}$ & $4.43-12.4 \mathrm{eV}$ \\
\hline NUV & $400-300 \mathrm{~nm}$ & $3.10-4.13 \mathrm{eV}$ \\
\hline MUV & $300-200 \mathrm{~nm}$ & $4.13-6.20 \mathrm{eV}$ \\
\hline FUV & $200-122 \mathrm{~nm}$ & $6.20-10.16 \mathrm{eV}$ \\
\hline H Lyman- $\alpha$ & $122-121 \mathrm{~nm}$ & $10.16-10.25 \mathrm{eV}$ \\
\hline VUV & $200-10 \mathrm{~nm}$ & $6.20-124 \mathrm{eV}$ \\
\hline EUV & $121-10 \mathrm{~nm}$ & $10.25-124 \mathrm{eV}$ \\
\hline
\end{tabular}

The sunscreen composition is 1,6-diisocyanatohexane, 2,5-diisocyanatomethylbic, 2,3-Bis(2-mercaptoethylthio) propane-1-thiol, [1,4]Dithian-2-yl-methanethiol, 2,9[1 ,4] Dithian-2-ylmethylsulfanylethanelthiol,

Pentaerythritoltetrakis, 3-Mercapto-propionic acid 3hydroxy2,2-bis-propylester, 3-Mercapto-propionic acid 3hydroxy-2-hydroxymethyl-2-propyl ester and sunscreen do. At least one of benzotriazole and benzophenone is used as a sunscreen, and it blocks $99 \%$ or more of UV rays entering the eyes, thereby preventing eye diseases such as glaucoma caused by UV rays.

Glass or plastic can be coated to reduce the amount of ultraviolet ray that passes through the transparent material. Such coatings are generally applicable to eyeglasses and automobile windows. UV filters are used to block the slightly sensitive invisible UV rays. The UV410 lens was tested spectrophotometrically and found to be completely blocked in the sub-410nm range. Figure 5 shows the transmission characteristics of the polarizing film. As a result of passing the $405 \mathrm{~nm}$ laser pointer through the developed lens, it was confirmed that it was completely blocked. Figure 6 shows the UV protection characteristics of a general lens, and Figure 7 shows the UV protection result of the 410 lens. 


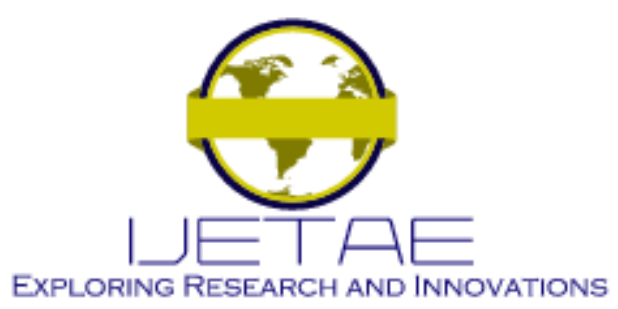

International Journal of Emerging Technology and Advanced Engineering

Website: www.ijetae.com (E-ISSN 2250-2459, Scopus Indexed, ISO 9001:2008 Certified Journal, Volume 11, Issue 11, November 2021)

\section{Polarizing Material Transmission Characteristics}

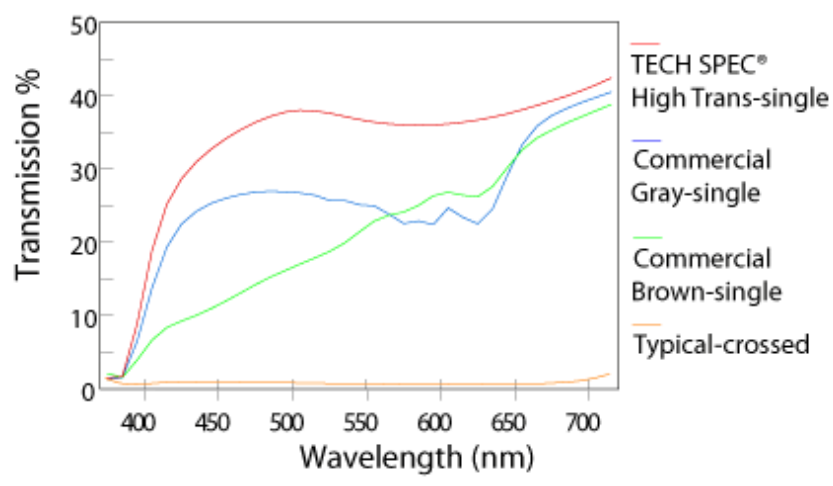

Fig. 5 Transmission characteristics of polarizing film

\section{F. Blue light reduction}

The CR39 and UV410 lenses were tested with a purple laser pointer. The purple laser pointer has a power of $5 \mathrm{~mW}$ and a wavelength of $405 \mathrm{~nm}$. Figure 11 shows a typical spectacle lens effect after $405 \mathrm{~nm}$ projection. The purple dots are clearly visible on the screen. Figure 12 shows the effect of the newly developed spectacle lens, with no visible purple spots.

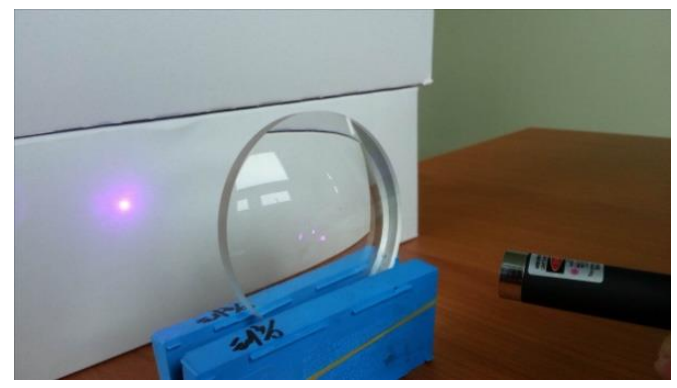

Fig. 6 Purple transmission property of CR39 lens

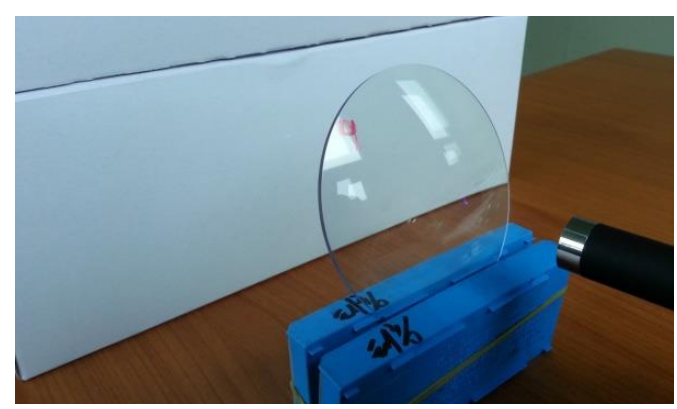

Fig. 7 UV blocking lens, purple beam cut off
We measured the transmittance of the developed sample lens using an ultraviolet visible light spectrophotometer. Figure 8 shows the difference in transmittance between the developed sample lens and the existing CR39 lens. Figure 9 shows the difference in transmittance between normal lenses and developed UV blocking lenses. The purple part is especially blocked, so more than $30 \%$ of the blue light is blocked overall.

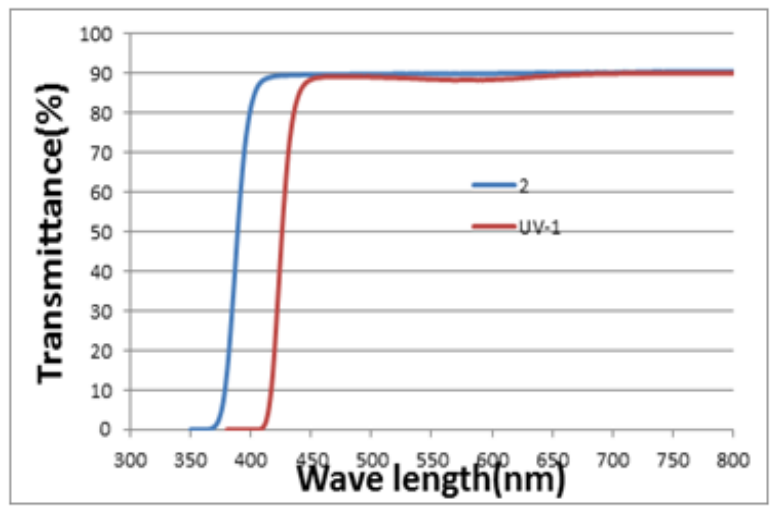

Fig. 8 Comparison spectrum of sample lens and general lens

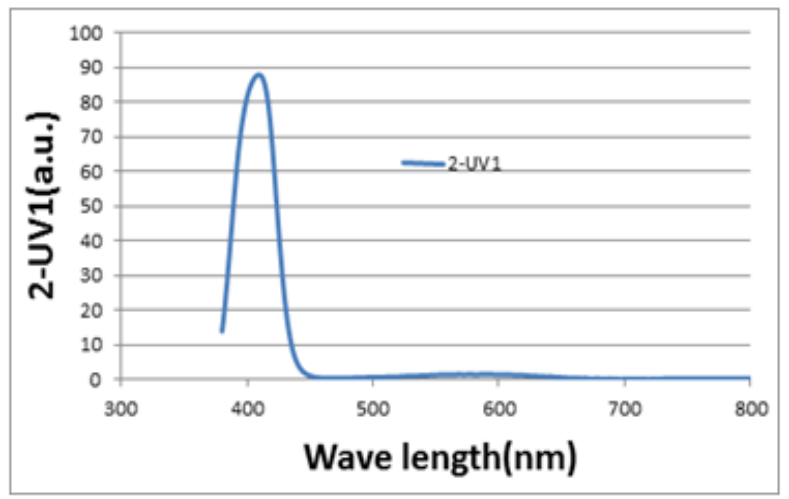

Fig. 9 Difference spectrum between sample lens and general lens

Figure 10 is a light transmittance of a polarizing lens with photochromic and UV blocking function. 


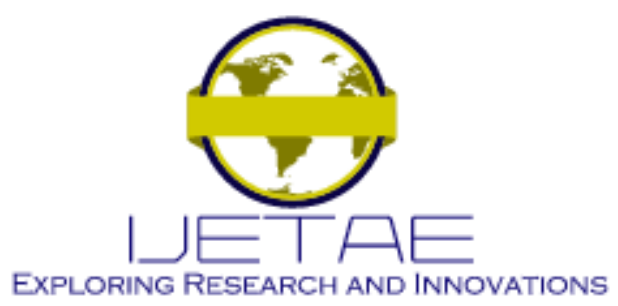

International Journal of Emerging Technology and Advanced Engineering

Website: www.ijetae.com (E-ISSN 2250-2459, Scopus Indexed, ISO 9001:2008 Certified Journal, Volume 11, Issue 11, November 2021)

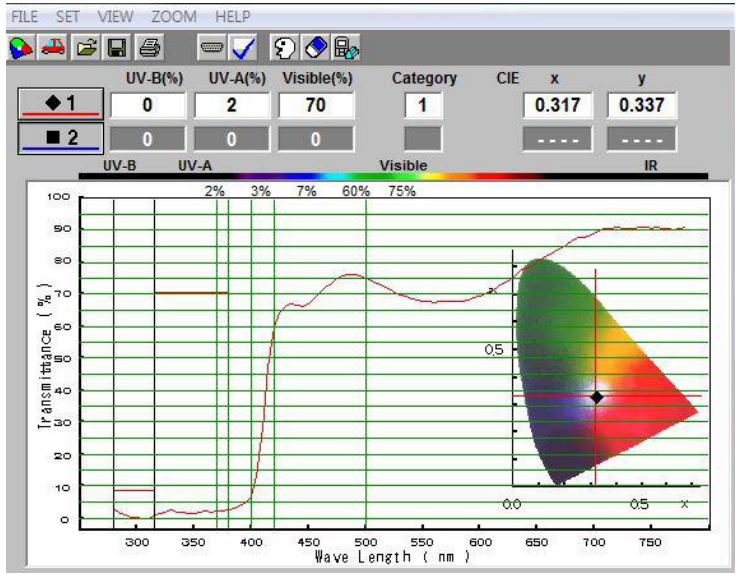

Fig. 10 Spectrum of polarized lenses with photochromic and UV protection

Blue light is part of the visible spectrum in the $380-450$ $\mathrm{nm}$ range. Blue light is emitted from smartphones and other electronic devices that have LED backlights installed. Natural light consists of a relatively continuous spectrum, including all colors. We should be concerned about the blue light peak of the LED flat panel. The blue frequency peak is clearly visible, an imbalanced energy distribution never seen in natural light. Not only does this artificial lighting cause oxidative stress in the eyes, which promotes medical conditions like age-related macular degeneration, but it can also disrupt hormonal balance, leading to chronic disease. Quite a few people suffer from temporary side effects when working on screens such as burns, stinging pains, eye stains, headaches, and unstable vision. However, blue light in the range of $465-496 \mathrm{~nm}$ is beneficial to health because it regulates the circadian rhythm. Therefore, it is advisable to limit exposure to wavelength bands exhibiting potentially harmful blue light and especially to the increased risk.

As smartphones, tablets, and computers become more common, more and more people spend more time looking at the screen, increasing the number of people suffering from eye strain. One of these causes is believed to be the blue light emitted by the display of such devices. The shorter the wavelength, the stronger the energy of light, which can cause eye strain.
Blue light next to ultraviolet light in the electromagnetic spectrum has a shorter wavelength than other visible light.

It also tends to spread and is thought to cause flicker in vision. Blue light reduction can be attempted by coloring yellow lenses that absorb blue light. However, some consumers may avoid wearing yellow lenses. Instead, it uses the AR coating principle to increase the reflectivity of blue light, preventing blue light from passing through the lens.

On the other hand, if transparent and conductive ITO is applied, electromagnetic wave shielding effect and antireflection effect can be realized at the same time. However, the refractive indices of $\mathrm{ZrO} 2$ and ITO are similar. Using this property, the anti-reflection effect and the electromagnetic wave shielding effect can be realized at the same time by improving the 5-layer anti-reflection layer to 6 layers. Table 3 shows the design values with electromagnetic shielding and anti-reflection effects applied, and Figure 11 shows the results of reflectance ratio after AR and EMI coating.

TABLE III

ANTI REFLECTION AND EMI COATING

\begin{tabular}{|c|c|c|c|c|c|c|}
\hline $\begin{array}{c}\text { Substrate } \\
\text { Sample }\end{array}$ & $\begin{array}{c}\mathrm{SiO}_{2} \\
(\mathrm{~nm})\end{array}$ & $\begin{array}{c}\mathrm{ZrO}_{2} \\
(\mathrm{~nm})\end{array}$ & $\begin{array}{c}\mathrm{SiO}_{2} \\
(\mathrm{~nm})\end{array}$ & $\begin{array}{c}\mathrm{ZrO}_{2} \\
(\mathrm{~nm})\end{array}$ & $\begin{array}{c}\mathrm{ITO} \\
(\mathrm{nm})\end{array}$ & $\begin{array}{c}\mathrm{SiO}_{2} \\
(\mathrm{~nm})\end{array}$ \\
\hline No.1 & 150 & 20 & 21 & 30 & 52 & 81 \\
\hline No.2 & 150 & 20 & 21 & 25 & 57 & 81 \\
\hline No.3 & 150 & 20 & 21 & 20 & 62 & 81 \\
\hline No.4 & 150 & 20 & 21 & 15 & 67 & 81 \\
\hline No.5 & 150 & 20 & 21 & 10 & 72 & 81 \\
\hline
\end{tabular}

In addition, by using the reflectivity of RGB, it is possible to change the surface color by changing the thickness of 5 layers and visualizing the color of the reflected light. 


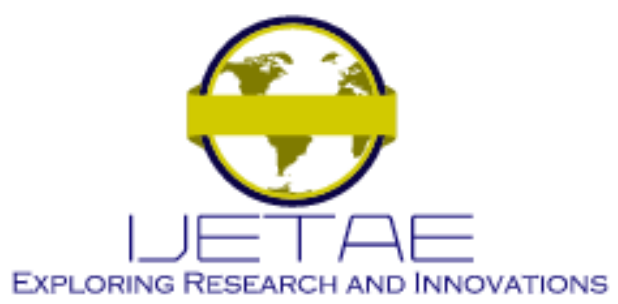

International Journal of Emerging Technology and Advanced Engineering

Website: www.ijetae.com (E-ISSN 2250-2459, Scopus Indexed, ISO 9001:2008 Certified Journal, Volume 11, Issue 11, November 2021)

TABLE IV

UV ICP ANALYSIS CONDITION

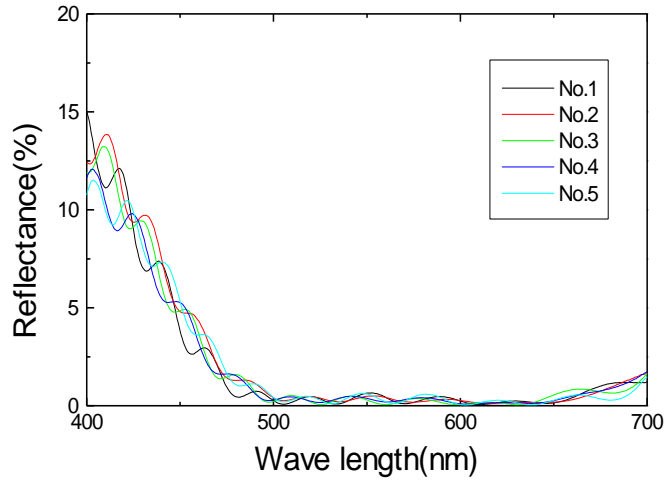

Fig. 11 Reflectance ratio after AR and EMI coating.

The electrical conductivity by ITO is proportional to the deposition thickness, and it changes in proportion to the electromagnetic shielding. Figure 12 shows that electrical conductivity and electromagnetic shielding effect are proportional.

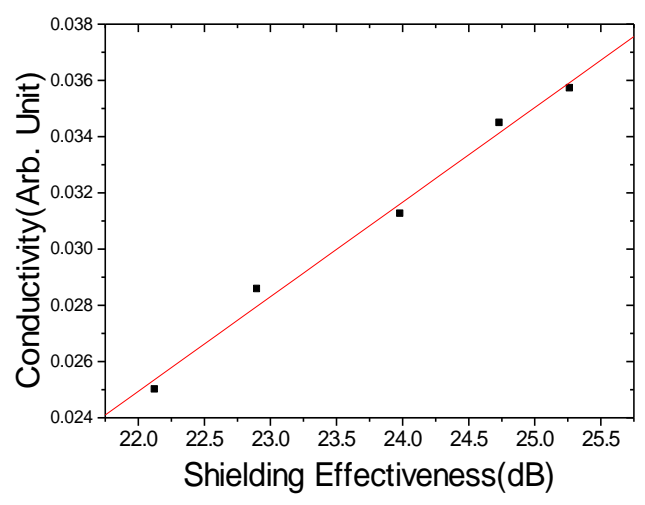

Fig. 12 Shielding effect vs. surface electric conductivity

\section{G. Monomer component analysis}

The components of UV blocking monomer and photochromic monomer were tested at the Korea Research Institute of Chemical Convergence. As the test equipment, an Inductively Coupled Plasma Spectrometer (ICP: iCAP 7400, Thermo elemental, USA) was used. ICP analysis conditions are shown in Table 4.

\begin{tabular}{|l|l|}
\hline Item & Condition \\
\hline Wavelength & $166 \mathrm{~nm} \sim 782 \mathrm{~nm}$ \\
\hline Nebulizer pump & $50(1.85 \mathrm{~mL} / \mathrm{min})$ \\
\hline RF power $(\mathrm{W})$ & 1150 \\
\hline Nebulizer flow (L/min) & 0.5 \\
\hline Auxiliary gas flow $(\mathrm{L} / \mathrm{min})$ & 0.5 \\
\hline
\end{tabular}

The inorganic elements contained in the samples were pretreated according to EPA 3051A (Microwave assisted acid digestion of sediments, sludges, soils, and oils), and then the inorganic elements were analyzed according to EPA 6010D (Inductively coupled plasma optical emission spectrometry). $\mathrm{Na}, \mathrm{K}, \mathrm{Mg}, \mathrm{Ca}, \mathrm{Ba}, \mathrm{Ti}, \mathrm{Zr}, \mathrm{Mn}, \mathrm{Cr}, \mathrm{V}, \mathrm{Fe}$, $\mathrm{Co}, \mathrm{Ni}, \mathrm{Cu}, \mathrm{Zn}, \mathrm{Al}, \mathrm{Si}, \mathrm{Sb}, \mathrm{P}, \mathrm{As}, \mathrm{Pb}, \mathrm{Bi}, \mathrm{B}, \mathrm{Se}, \mathrm{Cd}, \mathrm{Mo}$ and $\mathrm{Sn}$ were quantitatively analyzed. Eight elements such as $\mathrm{Na}, \mathrm{K}, \mathrm{Mg}, \mathrm{Ca}, \mathrm{Fe}, \mathrm{Al}, \mathrm{Si}$, and $\mathrm{P}$ were identified, and the detection limit was $5 \mathrm{mg} / \mathrm{kg}$. As a result of quantitative analysis, the content of $\mathrm{P}$ was the highest, followed by $\mathrm{Ca}$. Table 5 shows the results of quantitative analysis of inorganic components.

TABLE V

INORGANIC ELEMENT QUANTITATIVE ANALYSIS (MG/KG)

\begin{tabular}{|c|c|c|}
\hline Item & UV Protection & Photochromism \\
\hline $\mathrm{Na}$ & 33 & 26 \\
\hline $\mathrm{K}$ & 7 & 6 \\
\hline $\mathrm{Mg}$ & 6 & 51 \\
\hline $\mathrm{Ca}$ & 52 & 6 \\
\hline $\mathrm{Fe}$ & 12 & 11 \\
\hline $\mathrm{Al}$ & 9 & 18 \\
\hline $\mathrm{Si}$ & 6 & 424 \\
\hline $\mathrm{P}$ & 796 & \\
\hline
\end{tabular}




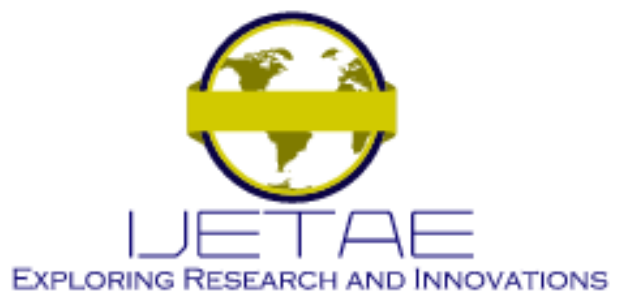

International Journal of Emerging Technology and Advanced Engineering

Website: www.ijetae.com (E-ISSN 2250-2459, Scopus Indexed, ISO 9001:2008 Certified Journal, Volume 11, Issue 11, November 2021)

\section{CONCLUSION}

Using a urethane-based monomer with a refractive index of 1.67 , we developed a polarized spectacle lens with UV blocking, blue light reduction, and photochromic functions. Although spectacle lenses with each independent function have been released, a spectacle lens with a refractive index of 1.89 with such a comprehensive function has never been developed. In particular, UV protection is important for glasses wearers who use concave or convex lenses. The developed spectacle lens completely blocks wavelengths below $410 \mathrm{~nm}$ of ultraviolet light and reduces blue light by more than $30 \%$. The photochromic function was restored to its original state in 2 minutes in the dark reaction and 5 minutes in the light reaction. The polarization degree showed a good result of 99.07. Anti-reflection and electromagnetic wave shielding functions are provided through multi-layer coating. The reflectance obtained about $0.1 \%$ and the electromagnetic wave shielding function was proportional to the ITO thickness. The result will be good for spectacle wearers and sunglasses lovers.

\section{REFERENCES}

[1] Kim Jun-won, Ahn Kwang-hyeon, Kim Hong-doo, Jang Tae-hyun. 1997. Photochromic 2- ( 1', 2' - dimethyl - 3' - indolyl )-3-( 2" methyl -3"- benzo [ b ] thiophenyl ) maleic anhydride and Synthesis and Characterization of Polystyrene Derivatives. Polymers, 21(3), $512-520$

[2] Moonsik Cho, Im Sanghyeon, and Junsoon Kim. 2005. Clinical usefulness and effectiveness evaluation of photochromic spectacle lenses. Journal of the Korean Ophthalmology Society, 46(9), 15631568

[3] Shin-Won Kang, Kang-Min Cho, Park Soo-Young, Yoon JeongHyeon, Lim Seon-Jeong. 2004. A Study on the Light-Induced Refractive Index Change of Photochromic Diarylethene Derivatives Using Optical Fiber-Planar Waveguide Couplers. Journal of the Korean Optical Society, 15(2), 109-113

[4] Chang-Nam Choi, Hee-Suk Ryu, Hyeong-In Park, Jong-Bae Kim, and Sang-Ryul Kim. 1999. Synthesis of Diarylethene Photochromic Pigments and Their Characteristics. Journal of the Korean Society of Textile Engineering, 36(2), 140-147
[5] Doo Hee Han. 2014. Development of a polarized lens for viewing stereoscopic movies. Proceedings of the Korean Society for Industry-Academic Technology Conference, (), 918-920

[6] Doo Hee Han. 2018. A Study on Polarized Glasses Lenses with Refractive Index 1.60 Photochromic UV Protection. Journal of Convergence Information, 8(1), 147-152

[7] Kim Ha-rim and Jeong Ju-hyun. 2019. A Study on the Optical and Physical Properties of Polarized Lenses. Journal of the Korean Ophthalmic Optics Society, 24(3), 309-313

[8] Youngkook Yoo and Eunjung Choi. 2013. A Study on the Blue Light Blocking Performance and Prescription of Blue Light Blocking Lenses. Journal of the Korean Ophthalmic Society, 18(3), 297-304

[9] Sangil Park. 2018. Photooxidation effect of A2E, lipofuscin in retina, by smartphone illumination and photooxidation prevention effect by blue light blocking lens. Journal of the Korean Ophthalmic Society, 23(4), 511-517

[10] Moonchan Park. 2019. Design of Coated Blue Light Blocking Lenses and Optical Characteristics According to Blue Light Blocking Rate. Journal of the Korean Ophthalmic Optics Society, 24(3), 301-307

[11] Ji-Hye Kim, Ha-Yeon Um, Eun-Ji Jo, So-Ra Kim, Mi-Jeong Park. 2019. Effect of blue light blocking lenses on readability and subjective symptoms when working with smart devices with different background colors. Journal of the Korean Ophthalmic Society, 24(1), 51-59

[12] Doo Hee Han. 2015. Development of UV-blocking spectacle lenses. Proceedings of the Korean Society for Industry-Academic Technology Conference, (), 266-267

[13] Park Sang-il. 2012. Effects of brown tinted lenses and UV-A blocking spectacle lenses on photooxidation of senile fluorescent pigments in the retina. Journal of the Korean Ophthalmic Society, 17(1), 91-97

[14] Choong-Seo Park, Young-Min Park, Dae-Hyun Kim, and Mi-Jung Park. 2007. Effect of UV-blocking lenses on UV-A-induced denaturation of antioxidant enzymes. Journal of the Korean Ophthalmic Society, 12(3), 97-103

[15] Heung-Soo Kim. 2018. Evaluation of UV blocking performance for convergence technology development of eyeglass lenses for vision correction. Journal of the Korean Convergence Society, 9(4), 93-98

[16] Ha Tae-wook, Lee Yong-hee, Choi Kyung-seo, Cha Jeong-won. 2003. Study on the UV-blocking effect of sunglasses lenses using nickel ferrite thin film $\mathrm{NixFe}_{3}-\mathrm{xO}_{4}$ ", Korea Ophthalmology Journal of the Korean Society of Science and Technology, 8(2), 25-29 